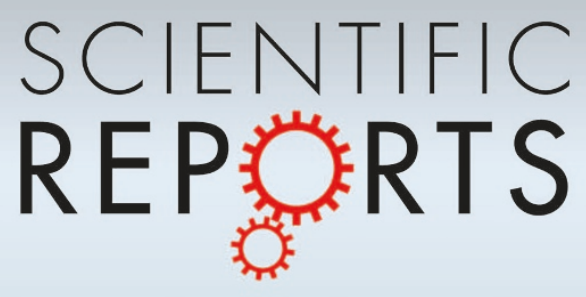

OPEN

SUBJECT AREAS:

PALAEONTOLOGY

EVOLUTIONARY ECOLOGY

Received

13 May 2014

Accepted

10 October 2014

Published

10 November 2014

Correspondence and requests for materials should be addressed to

X.Z. (xgzhang@ynu. edu.cn)

\section{Development and trunk segmentation of early instars of a ptychopariid trilobite from Cambrian Stage 5 of China}

\author{
Cen Shen',2, Euan N. K. Clarkson ${ }^{3}$, Jie Yang' ', Tian Lan', Jin-bo Hou' \& Xi-guang Zhang'
}

${ }^{1}$ Key Laboratory for Palaeobiology, Yunnan University, Kunming, Yunnan 650091, China, ${ }^{2}$ Faculty of Land Resources Engineering, Kunming University of Science and Technology, Kunming, Yunnan 650091, China, ${ }^{3}$ School of Geosciences, University of Edinburgh, West Mains Road, Edinburgh EH9 3JW, UK.

Many three-dimensionally preserved exoskeletons found from the middle Cambrian (Stage 5) Gaotai Formation in Guizhou, southern China, have been assigned to the ptychopariid trilobite Gunnia sp. They represent mainly a series of early instars, exhibiting some delicate structures and morphological variation associated with their trunk segmentation and early development. Morphometric and statistical analyses indicate that the transverse joint appears to occur with the full growth of the third axial ring of the protopygidium, which increases in size much more rapidly than its corresponding protocephalon with growth. The 'one by one' sequential release of thoracic segments from a transitory pygidium does not progress exactly in accordance with the development of the pygidial axis, whose axial rings increase at a relatively faster rate, and an 'immature ring' always appears initially at the rear end of the axis. These new data set up a testable model for revealing trilobite segmentation and provide fresh insights into the development, evolution and taphonomic surroundings associated with the Cambrian trilobites.

I rilobites are well known for their excellent fossil record and are widespread in the Palaeozoic deposits. As a stem arthropod group, abundant and highly diversified trilobites have long been a major focus of evolutionary and palaeobiological studies ${ }^{1}$. In particular, researches on trilobite ontogeny, moulting process and the body segmentation have recently attracted attention ${ }^{2-6}$.

Usually fossil trilobites are found directly on the surface of crack-out blocks of rock, and sometimes complete trilobites can be found, each of which may have all the components of the dorsal exoskeletons articulated one with another. Such exceptional material can clearly show the essential features of trunk segmentation, defined by the articulation(s). For trilobite ontogeny, the exact number of the articulations is conventionally regarded as direct evidence for the subdivision of the meraspid period (stages between the larval protaspid and the adult holaspid) into a series of degrees. However, this approach is often hindered by scarcity of material, especially where minute early instars are lacking. Trilobite fossils can also be obtained through acid dissolution of certain calcareous rocks. Without exception, the silicified or phosphatized specimens in the collection are always small and most of them are isolated skeletons of early instars; partially or fully articulated skeletons are rare. Nevertheless, acid liberated trilobites have also been used for ontogenetic studies, in which a series of growth stages ${ }^{1,7,8}$, or meraspides of various degrees ${ }^{6,9,10}$ have been established by taking advantage of morphometric and statistical analyses, as normally depending on a large number of specimens. Theoretically, any demonstration or conclusion resulting from such an analysis is reasonable, but not absolutely convincing unless the theoretical information can be directly compared with that measured from articulated individuals of the same taxon.

In this study the three dimensionally preserved exoskeletons assigned to the ptychopariid trilobite Gunnia sp. have enabled a detailed investigation to be undertaken on the post-embryonic development, in particular on some otherwise poorly understood aspects of the development of the early instars, including striking details of trunk segmentation with growth. Significantly, the superb material can provide convincing details for more precisely establishing how the development of the thorax, associated with segmentation took place.

\title{
Results
}

Geological setting and Material. All trilobites dealt with in this study were recovered from light grey or yellowish limestone nodules from the middle Cambrian (Stage 5) Gaotai Formation at an outcrop (107 $36^{\prime} 55.73^{\prime \prime} \mathrm{E}$, $26^{\circ} 15^{\prime} 4.57^{\prime \prime} \mathrm{N}$ ) near Balang village in Duyun, Guizhou, China (for locality details, see fig. 1 in Ref. 11 and for 


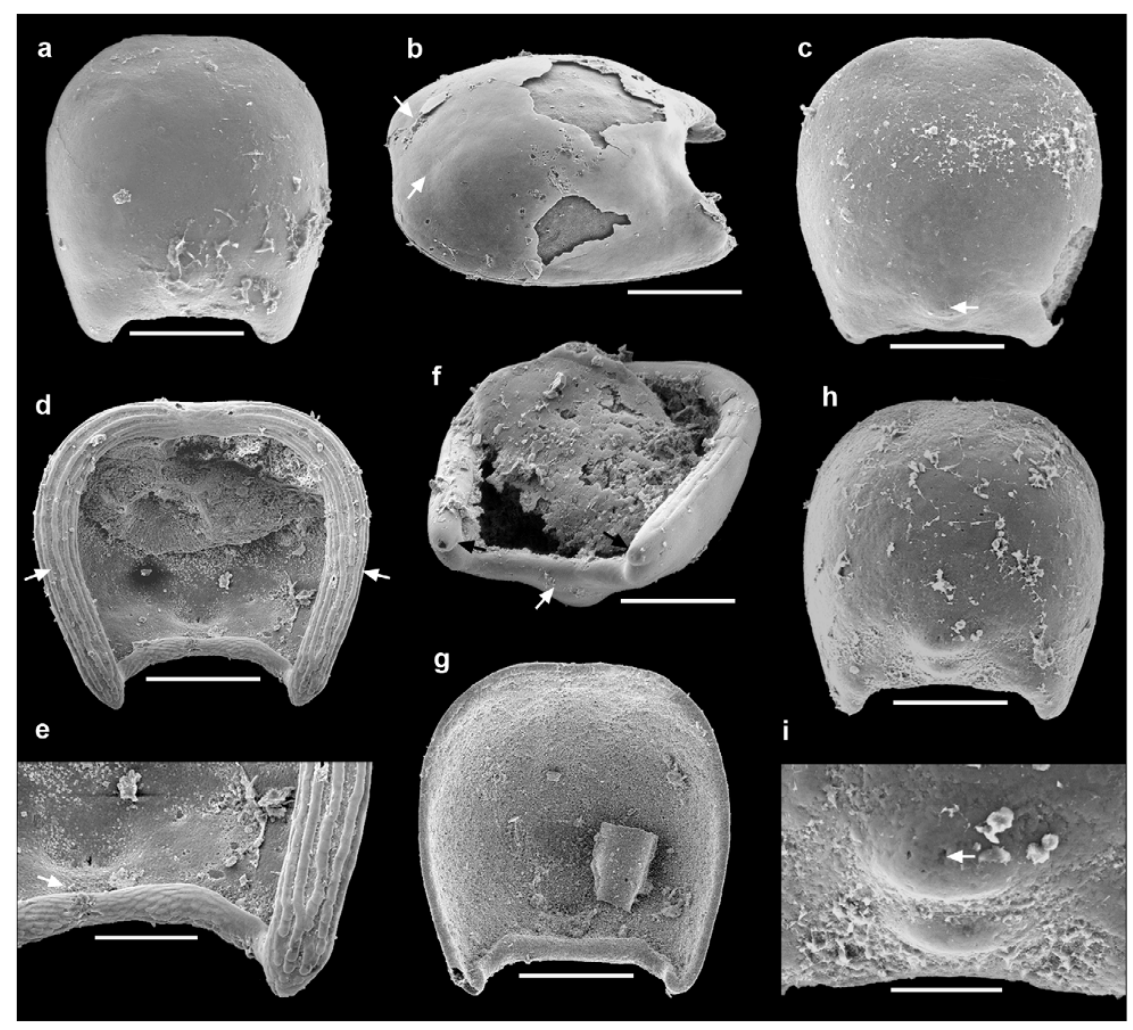

Figure 1 Protaspides of Gunnia sp. from Cambrian Stage 5 Duyun fauna. (a-c) stage 1 protaspides (P1): (a) YKLP 12027, dorsal view; (b) YKLP 12028, oblique lateral view, showing shallow fossulae (arrowed); (c) YKLP 12029, dorsal view, occipital ring bearing an occipital cut (arrowed). (d-i) stage 2 protaspides (P2): (d) YKLP 12030, ventral view, showing pseudo-bilateral asymmetry terrace lines (arrowed) and small granules on the surface of doublure; (e) details of (d), showing the ornament on left posterior lateral and posterior margins, a faint depression (arrowed) corresponding to the first axial ring behind the occipital ring; (f) YKLP 12031, oblique postero-ventral view, showing the first axial ring (white arrowed), fine terrace lines and genal spines (black arrowed); (g) YKLP 12032, ventral view, showing one pair of short genal spines and doublure developed along posterior margin; (h) YKLP 12033, dorsal view, showing one prominent axial ring behind occipital ring; (i) detail of (h), showing the occipital ring with an occipital cut (arrowed) and an axial ring behind. Scale bar equals $200 \mu \mathrm{m}$, except for (e) and (i) $100 \mu \mathrm{m}$.

outcrop details, see fig. DR1 in Ref. 12). Apart from these trilobites there are numerous lingulate brachiopod valves, various small shelly fossils, some bradoriid carapaces, rare scalidophoran embryos ${ }^{11}$, and many exoskeletons of the eodiscoid trilobite Pagetides qianensis ${ }^{6}$, which as a key index fossil, confirms the geological age for this fossil assemblage. In addition, many 'trace fossils', in the form of small-sized coprolites of unknown affinity have also been collected from the same bed.

Of these isolated trilobite exoskeletons the majority are protaspides (Fig. 1a-i) and meraspides (Figs. 2a-i, 3a-m) of Gunnia sp., only a few holaspid cranidia (Fig. $2 \mathrm{j}$ ) and pygidia (Fig. $3 \mathrm{n}$ ) that have been tentatively assigned to this species have been directly identified from the crack-out specimens-the limestone nodules coming from the same horizon within the Balang outcrop.

Many other trilobite exoskeletons (including more than thirty protaspides), with notable variation in overall outline of their dorsal shields and the marginal spinosity, probably come from four separate taxa of uncertain affinity (Fig. 4a-1), of which only one group with unique glabellar and protopygidial features has been firmly identified as consisting of early instars related to some co-occurring corynexochid meraspides and holaspides (Fig. 4g-1).

94 isolated exoskeletons and 15 crack-out specimens of Gunnia sp. (including 31 protaspides, 30 cephala and cranidia, 39 pygidia, 4 thoracic segments and 5 librigenae), and 12 protaspid or meraspid exoskeletons of affinity uncertain were used for this study. Because of incomplete preservation 27 specimens were registered (YKLP 12109-12135) but were unable to be measured for the construction of bivariate plots. All these trilobites (121 in total) are deposited in the collections of the Key Laboratory for Palaeobiology, Yunnan University in Kunming, China.

Systematic palaeontology. The trilobite descriptive terminology used here follows that of Chatterton and Speyer ${ }^{1}$, Whittington ${ }^{13}$, Hughes et al. ${ }^{14}$ and Zhang and Clarkson ${ }^{6}$.

Class Trilobita Walch, 1771

Order Ptychopariida Swinnerton, 1915

Family Ptychopariidae Matthew, 1887

Genus Gunnia Gatehouse, 1968

Type species. Gunnia lutea Gatehouse, 1968 from the Middle Cambrian Tindall Limestone, Litchfield, Northern Territory, Australia ${ }^{15}$.

Diagnosis. A genus of Ptychopariidae with a faint eye ridge. Glabella truncate-conical, with 3-4 pairs of weakly incised lateral furrows. Preocular field and preglabellar field almost equal in length (sag., exs.). Eye ridge slightly oblique and curving rearwards; mediumsized palpebral lobe relatively located in the middle or posterior of the glabella. Anterior branch of facial suture runs evenly outwards to a rounded inflection. Thorax of 14 segments.

Remarks. Gunnia was established by Gatehouse in 1968 but because it is a rare trilobite its taxonomic position within Ptychopariidae has been a subject of much debate for a long time ${ }^{16,17}$. With such rare occurrence in Cambrian strata, and since it is distributed only in geographically limited areas, this ptychopariid trilobite has been regarded as an 'endemic' taxon. Subsequently, in a major revision ${ }^{18}$ some specimens previously assigned to other ptychopariid taxa from 


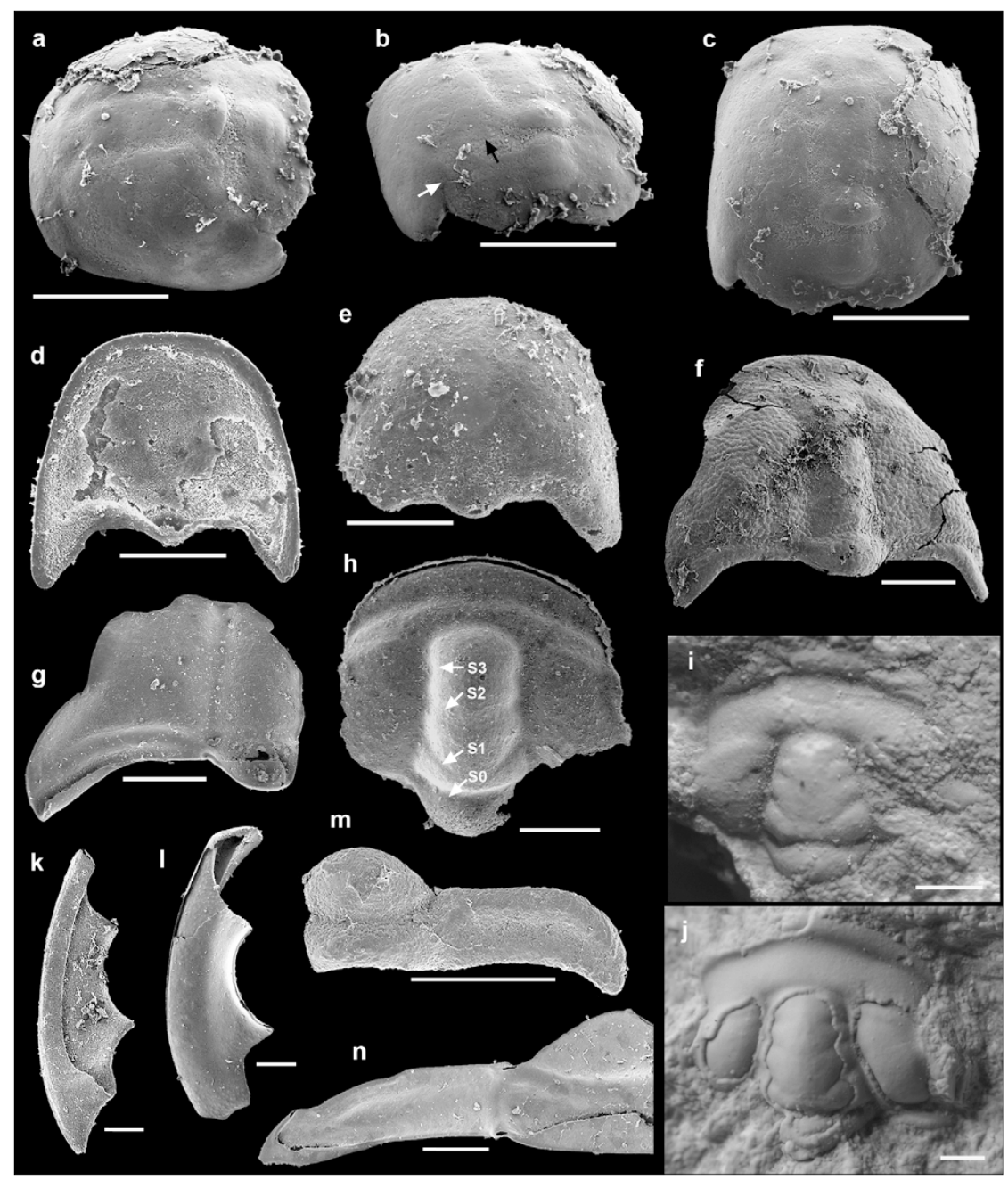

Figure $2 \mid$ Cephalon (or cranidia), librigenae and thoracic segments of Gunnia sp. from Cambrian Stage 5 Duyun fauna. (a-c) YKLP 12034, degree 0 meraspis (M0), cephalon with a pair of broad genal spines, articulated with its transitory pygidium, which displays three axial rings: (a) oblique latero-dorsal view; (b) oblique postero-dorsal view, showing the secondary coating (white arrowed) and the first transverse joint (black arrowed); (c) dorsal view. (d) YKLP 12035, cephalon of meraspid degree 0 (M0), ventral view; (e) YKLP 12036, cephalon of meraspid degree 1 (M1), dorsal view; (f) YKLP 12037, cranidium of meraspid degree 3 (M3) with fine granules on the outer surface, dorsal views. (g) YKLP 12038, fragmentary cranidium of meraspid degree 4 (M4), ventral view, showing the broad right genal spine with partially survived doublure along the posterior margin. (h) YKLP 12039, cranidium of meraspis, clearly showing deep occipital furrow and three glabellar furrows (arrowed). (i), (j) crack-out cranidia, dorsal views: (i) YKLP 12040, late maraspis showing partially preserved palpebral lobe; (j) YKLP 12041, early holaspis showing well-preserved impressions of three paired glabellar furrows. (k), (l) Librigena of Gunnia sp.: (k) YKLP 12042, ventral view; (l) YKLP 12043, dorsal view, showing fine granules on the surface. (m) YKLP 12044, dorsal view, right half of a meraspid thoracic segment; (n) YKLP 12045, ventral view, right half of a holaspid thoracic segment. S0 = occipital furrow; S1-S3 = glabellar furrows. Scale bars for $(\mathrm{a}-\mathrm{h}) 300 \mu \mathrm{m}$; for (i), (j) $1 \mathrm{~mm}$; for (k-n) $200 \mu \mathrm{m}$.

southern China ${ }^{17,19,20}$, as well as further material lately discovered from the Indian Himalaya, were all referred to this genus. Until now, many holaspid cranidia, pygidia and librigenae of Gunnia have been described from strata of Cambrian Series 2 (Stage 4) or Series 3 (Stage 5) in Australia, southern China, and India. Recently this genus has become even 'popular' with some species formerly assigned to Ellotia and Yiliangaspis being regarded as junior synonyms of Gunnia $^{16-18}$. It seems apparent that Gunnia exhibits a good number of distinguishable characters of its own, and accordingly here we follow Kruse ${ }^{16}$ and Peng et al. ${ }^{18}$ in leaving it at generic rank.

Gunnia sp.

Figures 1a-i, 2a-n, 3a-n, 5-7

Type locality and horizon. Cambrian Stage 5 Gaotai Formation at the Balang outcrop in Duyun, Guizhou, southern China.

Description. Cranidium (Fig. 2j) with anterior margin slightly arched forward. Anterior border convex; anterior furrow deep and broad. Glabella truncate-conical and strongly inflated, with three pairs of faint lateral furrows (S1-S3). Occipital ring semielliptical; occipital furrow nearly straight, but much more deeply incised laterally. Preglabellar field broad, with the same length (sag.) as the preocular field. Eye ridges prominent, slightly curving posteriorly, connected to palpebral lobes. Librigena (Fig. 2k, 1) bearing broad genal spine, wide lateral border, and gently impressed lateral border furrow. Doublure broad underneath lateral border and genal spine, ornamented with faint ridges. Thoracic segment (Fig. 2m, n) elongated, with distinctly impressed pleural furrow. It is connected to adjacent parts of the exoskeleton via a 'Line articulation', with its free part bent postero-laterally. In ventral view, doublure developed beneath articulating half ring and free extremity. Pygidium (Fig. 3n) semicircular in outline with smooth curved posterior margin. Axis prominently convex, bearing at least 7 rings, clearly defined by transverse furrows. Anterior margin slightly inflected laterally and 


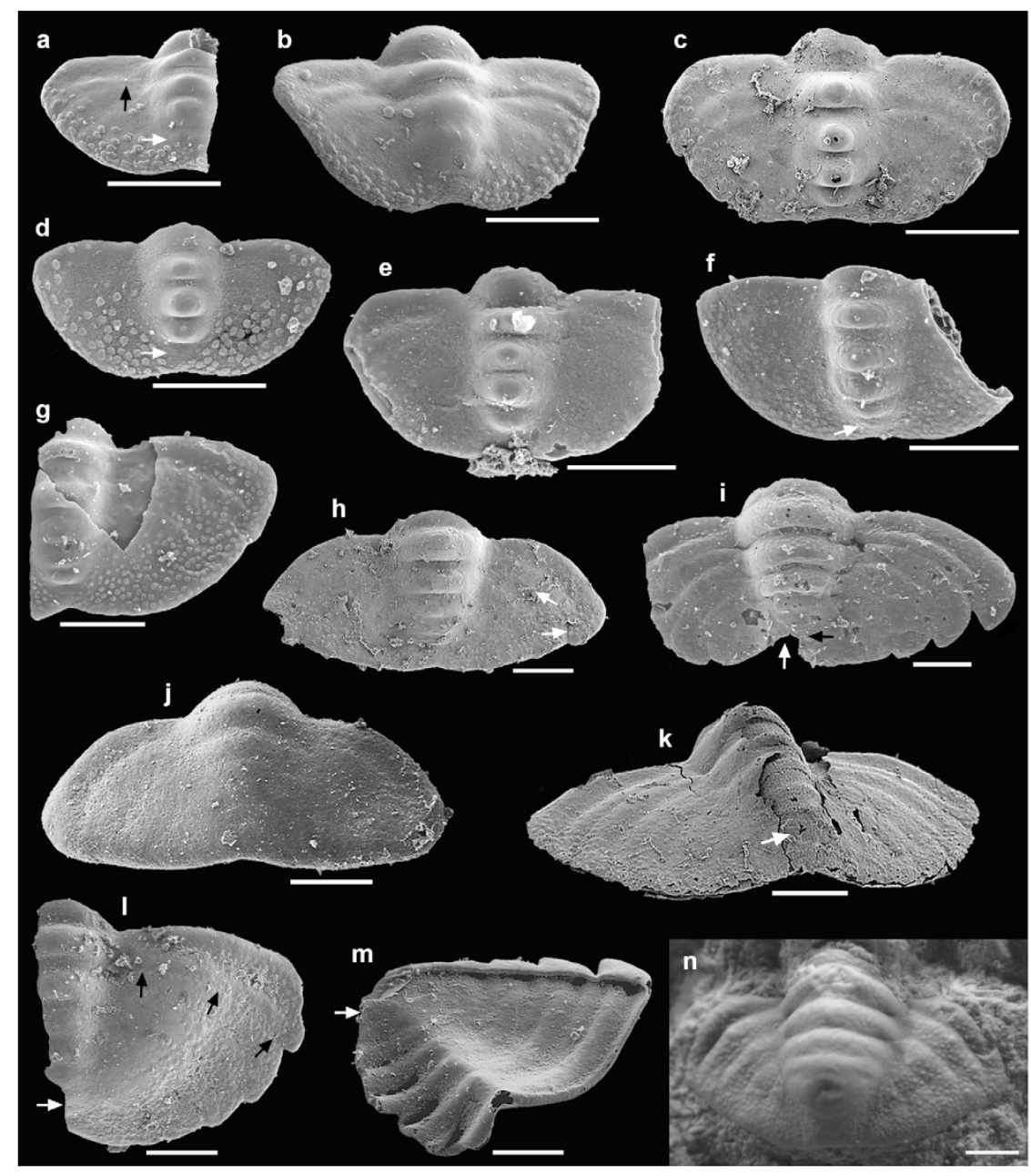

Figure 3 Meraspid and holaspid pygidia of Gunnia sp. from Cambrian Stage 5 Duyun fauna. (a) YKLP 12046, meraspid degree 0 (M0b), dorsal view, showing the early development of the fourth immature axial ring (white arrowed) and the second transverse joint (black arrowed). (b) YKLP 12047, meraspid degree 1 (M1a), dorsal view, showing three axial rings and an anteriorly articulated segment. (c) YKLP 12048, meraspid degree 1 (M1a), dorsal view, showing three prominent axial rings and an anteriorly articulated segment. (d) YKLP 12049, meraspid degree 1 (M1b), dorsal view, showing three distinct axial rings and the faint occurrence of the fifth immature axial ring (white arrowed). (e) YKLP 12050, meraspid degree 2 (M2a), dorsal view, showing four prominent axial rings. (f) YKLP 12051, meraspid degree 2 (M2b), dorsal view, showing four axial rings and the weakly developed sixth immature axial ring. (g) YKLP 12052, meraspid degree 3 (M3a), dorsal view, right half of the pygidium showing five axial rings. (h) YKLP 12053, meraspid degree 4 (M4a), dorsal view, showing weakly developed articulation (arrowed). (i) YKLP 12054, meraspid degree 4 (M4b), dorsal view, showing the faintly developed seventh axial ring (black arrowed) and possibly healing of injury (white arrowed). (j) YKLP 12055, meraspid degree 5 (M5a), dorsal view, displaying five axial rings, no sign of articulation. (k) YKLP 12056, meraspid degree 5(M5b), oblique dorsal views, showing minute granules on the outer surface, with the eighth axial ring (arrowed) weakly developed. (1-n) late meraspid or early holaspid pygidia with seven axial rings: (1) YKLP 12057, meraspid degree 6 (M6a), right half, dorsal view, showing poorly developed articulation (black arrowed) and possibly the eighth axial ring (white arrowed). (m) YKLP 12058, meraspid degree 6 (M6b) or early holaspis, right half, antero-ventral view, showing at least six and possibly the ninth axial ring (arrowed). (n) YKLP 12059, crack-out holaspid pygidium, dorsal view, showing highly elevated axis with seven axial rings. Scale bars, $200 \mu \mathrm{m}$, except for (n) $1 \mathrm{~mm}$.

backwardly. Pleural region convex with four pairs of pleural furrows faintly impressed. Border evenly arched and defined by faint border furrow.

Ontogeny. 109 specimens assigned to Gunnia sp. mainly consist of instars of various early growth stages and degrees. Most of them are disarticulated exoskeletons; only a few cranidia (Fig. 2i, j) and pygidia (Fig. 3n) were directly identified from the matrix. In the bivariate plots (Fig. 5) it is clearly shown that the size ranges provide no conclusive indications for assignment of these specimens to a certain meraspid degree or holaspid stage, although the cephala or cranidia display a relatively wide size range with growth (Fig. 5a). Nevertheless, many isolated pygidia in our collection display a remarkable variation in their axial rings, which as careful examination has revealed, increased with growth in a traditionally recognized way. Possibly so did the protaspides, since the axis of their protopygidia bearing no axial ring or only one has been recognized. Thus based on the development of the trunk segmentation, as well as the variation in size and morphology of these exoskeletons, we can firmly refer some of them into instars belonging to a few stages and degrees, and provide a detailed, though incomplete description of the development process starting with the earliest representatives hitherto known-the protaspides, as follows.

Protaspid period. The 31 protaspides referred to Gunnia sp. show overall morphological similarities: a subrounded, moderately convex dorsal shield, poorly elevated glabella, faint axial furrows and distinct occipital ring. However, the protopygidial axis is weakly developed, displaying no axial ring (Fig. 1a-c) or only one (Fig. 1d-i). As with a transitory pygidium, more rings would be added to the protopygi- 


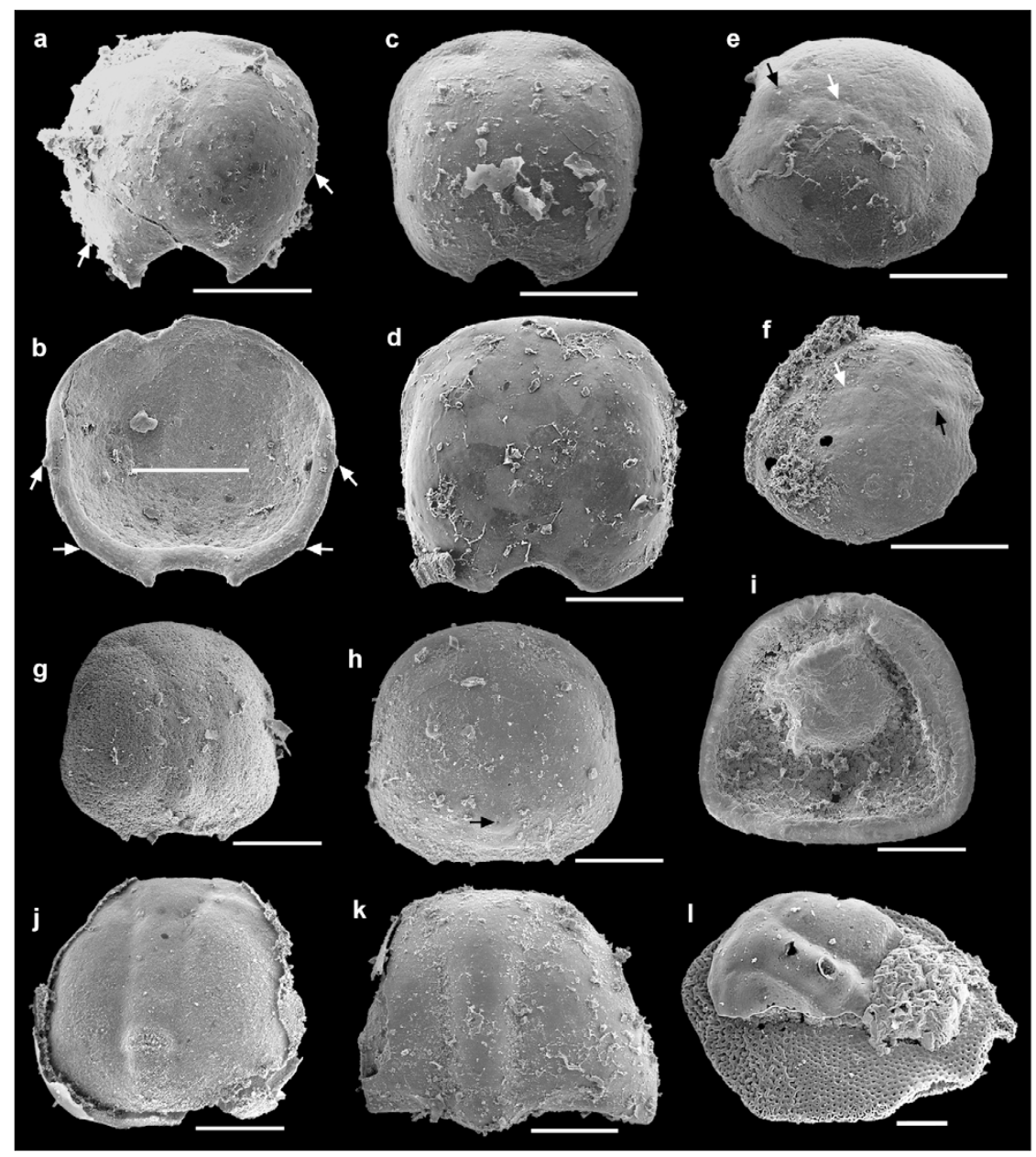

Figure $4 \mid$ Trilobite protaspides and meraspides from Cambrian Stage 5 Duyun fauna. (a), (b) genus and species indet. 1 showing paired anterior fixigenal spines and mid-fixigenal spines (arrowed), posterior fixigenal spines and fine lines on the doublure: (a) YKLP 12060, dorsal view; (b) YKLP 12061, ventral view. (c), (d) genus and species indet. 2, dorsal shield tetragonal in outline with short and broad posterior fixigenal spines: (c) YKLP 12062, dorsal view, showing deep fossulae; (d) YKLP 12063, dorsal view. (e), (f) genus and species indet. 3 with sagittal glabellar furrow (white arrowed) and occipital cut (black arrowed): (e) YKLP 12064, oblique dorsal view; (f) YKLP 12065, laterodorsal view, showing paired anterior fixigenal and midfixigenal spines. (g)-(l) corynexochid exoskeletons: (g) YKLP 12066, protaspis of stage 1 (P1), dorsal view, showing moderately elevated glabella, deep fossulae and axial furrows, inflate occipital ring and two pairs of protopygidial marginal spines. (h) YKLP 12067, protaspis of stage 2 (P2), dorsal view, showing occipital cut (arrowed) and one axial ring of protopygidium; (i) YKLP 12068, ventral view, showing well developed doublure and survived hypostome; (j) YKLP 12069, late developmental stage protaspis, oblique dorsal view, showing eye ridges and protopygigium with at least two axial rings; (k) YKLP 12070, meraspid cephalon, dorsal view, showing moderately convax axis with the anterior lobe expanded remarkably. (1) YKLP 12071, late meraspid cranidium fused to an echinoderm sclerite, oblique dorsal view. All scale bars, $200 \mu \mathrm{m}$.

dium with growth, thus the number of axial rings has also been applied as a criterion for the division of protaspid instars here, and the axial segment-based division of protaspid stages is fundamentally in accordance with that for the division of either meraspid degrees or holaspid stages.

There is a distinct 'gap' between the protopygidium with one axial ring and the meraspid degree 0 pygidium with three axial rings (Fig. 5b). That is, the gap may therefore just indicate an absence of some supposed protaspides (P3), of which each protopygidium bears two axial rings. As a result during the protaspid period the protopygidium would increase in size much faster than the corresponding protocephalon. Given this essential feature relevant to the axial variation of these early instars, our detailed investigation mainly focusing on protopygidia, has offered fresh data for a better understanding of the early development of this ptychopariid trilobite.

Meraspid period. Dorsal shields assigned to this developmental period, except one with an articulated cephalon and pygidium (Fig. 2ac), are all isolated cephala (or cranidia) (Fig. 2d-h), thoracic seg- ments (Fig. $2 \mathrm{~m}, \mathrm{n}$ ) and pygidia (Fig. $3 \mathrm{a}-\mathrm{m}$ ). It should be noted that without direct evidence from additional articulated exoskeletons the exact position these disarticulated sclerites represent within the developmental process is hard to determine, especially for cranidia. However, as based on inference from the analysis of sclerite articulation and axial segmentation on a transitory pygidium, some early meraspid pygidia may be tentatively differentiated into a series of degrees (Fig. 5b). Moreover, for isolated cephala (or cranidia) the assignment mostly relies upon their sizes, as focusing on a comparison of the length of the posterior margin between the genal spines with that of the anterior margin of a pygidium, the approximate equality in the length of the margins indicates that corresponding exoskeletons belong to the same meraspid degree.

We identify the only articulated specimen (Fig. 2a-c) as meraspid degree 0 for three reasons: (i) this specimen has clearly displayed three fully-grown axial rings behind the occipital rings. As demonstrated in this study, with the appearance of the fourth axial ring the first thoracic segment would be released from a late meraspid degree 0 pygidium, which then becoming an early meraspid degree 1 pygi- 

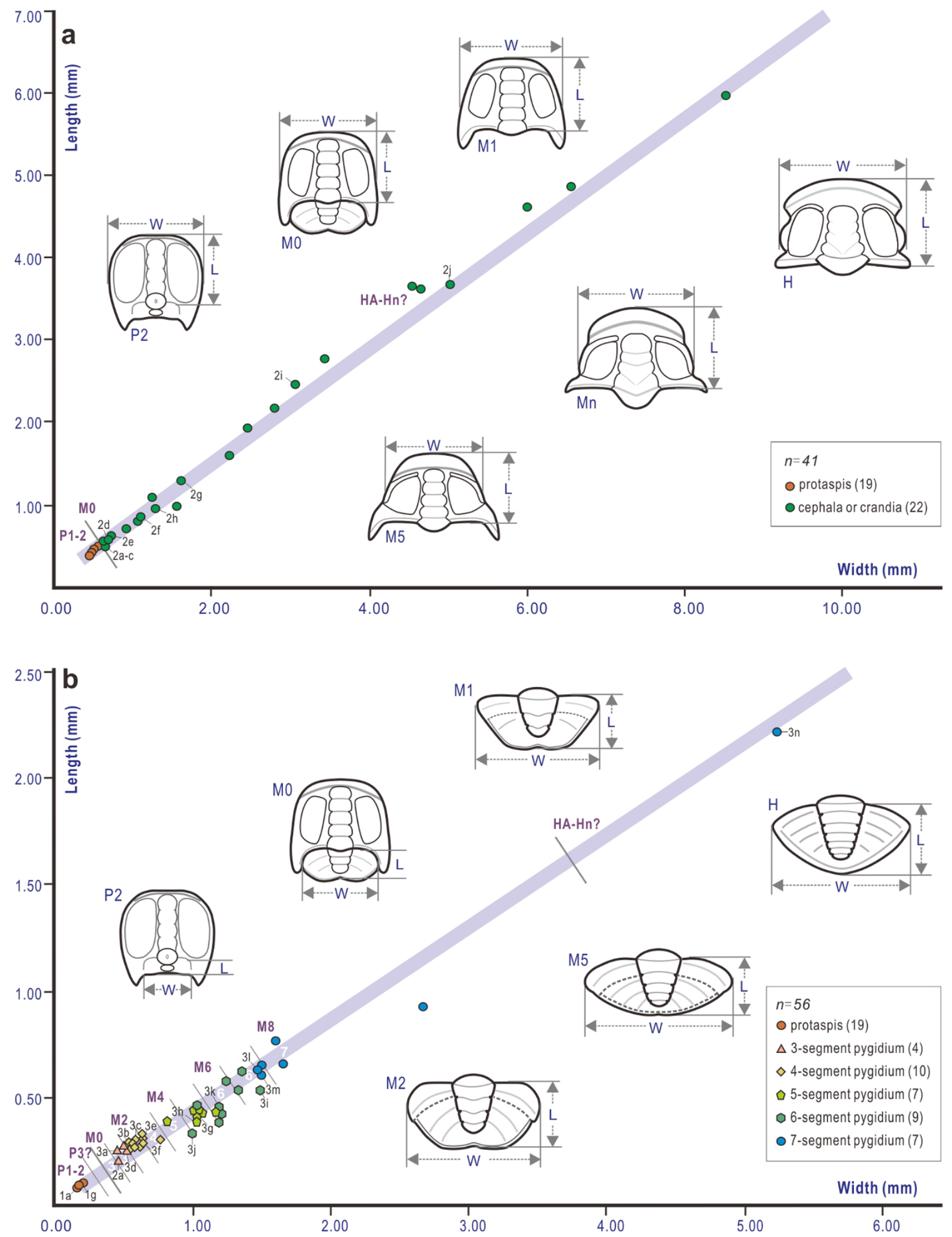

Figure 5 Bivariate plot diagrams of Gunnia sp. All measured specimens represented by fine points either in (a) or (b) show an approximately isometric growth pattern, with some figured specimens labeled (e.g., 2a representing Fig. 2a; 3n representing Fig. 3n, etc.). (a) 41 cephala and cranidia (including 19 protocephala). The boundary for Protaspid/Meraspid is defined by early instar specimens dealt with here; without enough material, the boundary in (b) for Meraspid/Holaspid is determined by matching the width of the posterior margin of a cranidium to that of a pygidium situated near the boundary. (b) 53 pygidia (including 19 protopygidia). The growth ratio (1.15) is determined by measuring all of early meraspides, and then this ratio is applied to the division of succeeding meraspid degrees and holaspid stages. The number in the slope line indicates the visible axial rings of a pygidium correspondingly. The original measurement of all specimens applied for making this figure can be found from Supplementary Tables S1 and S2 in the online version. 
dium displaying also three axial rings (Fig. 3a, b). Thus we can deduce the occurrence of the first transverse joint between the protocephalon and protopygidium is in association with the full development of the third axial ring. (ii) the upper portion of the meraspid (degree 0 ) pygidium is fused to the genal spine (Fig. 2a-c), this means that diagenesis (phosphatization) may have obscured the slit between the pygidium and the genal spine, and most likely also the first transverse suture, which, although so weak, is still traceable (Fig. 2b). (iii) according to the size, the missing pygidium of the meraspid cephalon (Fig. 2d) is obviously smaller than the pygidium of the specimen in question (Fig. 2a-c).

There are some major morphological changes during the development of meraspid period: (i) in general the pygidium increased in size substantially relative to its corresponding cephalon, but the increase is not so dramatic as that expressed by preceding protaspides. (ii) with the appearance of the facial sutures, librigenae increasingly became prominent, and so did the eye ridges and palpebral lobes. (iii) the number of axial rings of the pygidium increased from three up to seven. (iv) the genal spines became wider and stronger; the $\omega$ shaped posterior margin of the transitory pygidium becoming semicircular. (v) The meraspid pygidia with the same number of axial rings are roughly scattered together in the bivariate plot diagram (Fig. 5b), forming a series of "clusters" that to some extent overlap.

Holaspid period. Without enough data derived from available material, we cannot properly refer these holaspid exoskeletons precisely to any certain growth stages, nor their morphological variations with successive growth. However, a few late meraspid and holaspid cranidia of relatively large size (Fig. $2 \mathrm{i}$, j) share some traceable features with preceding late meraspid cranidia. In addition, some isolated, relatively large librigenae (Fig. $2 \mathrm{k}, 1$ ), according to their size, are most likely to have been shed from holaspid instars. Based on the shape of the facial suture determined from inner margin of these librigenae, the suture pattern is opisthoparian.

Two unique ontogenetic modifications displayed by these earlier instars can be summarized as follows:

Terrace lines. Terrace lines, long recognized in trilobites, have been presumed to be a sensory apparatus for current monitoring ${ }^{21}$, or may have functionally increased friction during burrowing ${ }^{22,23}$. As demonstrated here, at least some early instars (protaspides) of Gunnia sp., have had minute terrace lines well-developed on their lateral doublures during ontogeny. By considering the alternative hypothesis of mechanical function previously proposed, we have no additional evidence to verify whether the fine terrace lines may have played a role as a current monitor or just simply increased friction for some sort of movement, especially since the terrace lines are so fine and only appear on the narrow surface of the doublure. Curiously such fine lines appear to vanish with subsequent growth, since none has been found on the doublure of either the cephalon or pygidium of a meraspis or holaspis (e.g. Figs. 2d, 3m). Nevertheless, as the first record of this kind of fine structure found in trilobite protaspides, it is potentially significant for understanding the function of the terrace lines associated with the mode of life for this ptychopariid trilobite.

At the first glimpse, the terrace lines on both lateral doublures appear to be bilaterally symmetrical. However a close view reveals that the pattern of fine ridges on the right surface of the doublure is not exactly the same as that on the left (Fig. 1d). That is, it is an example of bilateral, or pseudo-bilateral asymmetry.

Facial sutures. It is generally accepted that the facial sutures played an important role during ecdysis in many trilobites, but in phacopids the facial suture was nonfunctional in the adult stages while it was useful in earlier stages of its development ${ }^{24}$. There is no sign of a facial suture or librigenae in any of the protaspides of Gunnia sp., nor even for some early meraspides (Fig. $2 \mathrm{a}-\mathrm{e}$ ). During the subsequent mer- aspid development onwards, the facial suture, which outlines the inner edge of the missing librigenae along both lateral margins has been determined from some meraspid cranidia (Fig. $2 \mathrm{f}-\mathrm{h}$ ). It seems certain that the junction line between cephalon and thorax (or pygidium) became functional earlier in moulting during the early development phase than the facial suture became obvious. This indicates that with or without the facial suture, there may be two different ways of moulting for some meraspid instars of Gunnia sp. This phenomenon has also been observed in the ontogeny of Protopeltura aciculata: as a result its disarticulated cephalon of meraspid group 1 bears attached librigenae ${ }^{25}$. It seems that, as predicted by Clarkson et al. $^{26}$ on the basis of investigation on Ctenopyge (Eoctenopyge) angusta, the ecdysial mode could have changed during ontogeny.

As based on some holaspid cranidia and isolated librigenae (Fig. 2k, 1), the facial suture of Gunnia sp. belongs to the opisthoparian type. Because to date no visual structure has been determined from a protaspis of this species, it seems certain that with growth the librigenae increase in size remarkably from the meraspid period onwards, and for some early meraspides the initially developed librigenae should be very small and antero-laterally situated. Thus the posterior section of the facial sutures is unlikely to reach the posterior border of the cephalon, since it bears a pair of strong genal spines. Instead, the facial suture may only cut through the lateral border, and in this case the facial suture of these early instars should represent the proparian condition. In other words, the facial suture would shift from the lateral border to the posterior border with subsequent growth. Nonetheless, this is not conclusive because the inference is based on observation of limited number of holaspid cranidia and librigenae, and how the transfer happened remains obscure. An alternative explanation is that the doublure attached to either lateral margin of some protaspides (Fig. 1d-f) might actually be the undeveloped librigena, which, however, bears only the ventral half of the genal spine, and may be completely lost along the facial suture (Fig. 1g). Additional material is required to verify the hypothesis, in particular, how such a "half" genal spine become fully developed with growth.

Segmentation. The superb trilobite exoskeletons from the Duyun fauna clearly show how segmentation occurred with growth.

Release of thoracic segments. Traditionally it seems apparent that with the appearance of a visible axial ring terminally added to the axis, a new transverse joint started to develop in the transitory pygidium. This would finally lead to the formation of a new thoracic segment. Such a mode of meraspid development (anamorphosis) has long been recognized ${ }^{27}$ and conventionally applied to ontogenetic studies on many trilobite lineages ${ }^{4,9,28-30}$, including the ptychopariid Gunnia sp. herein.

As demonstrated here the protopygidium of the latest protaspides (P2) so far known bears only one axial ring behind the occipital ring (Fig. 1d-i), whereas the earliest meraspis (M0) in our collection displays three axial rings (Fig. $2 \mathrm{a}-\mathrm{c}$ ). Most likely, this indicates that instars belonging to protaspid stage (P3) have not been obtained; these should bear two pygidial axial rings. During subsequent development with the appearance of the third ring, the protopygidium would start to separate from the protocephalon through the first transverse joint in the exoskeleton, in the process of becoming meraspid degree 0 ( $\mathrm{M} 0 \mathrm{a})$. Accordingly, some of the smallest transitory pygidia representing this degree do show three axial rings (Figs. 2a-c, 3a), and with the appearance of the fourth ring the first thoracic segment would start to release from the meraspid pygidium, which then became an early meraspid degree 1 instar displaying also three axial rings (Fig. 3d). In this way these isolated transitory pygidia with three axial rings are representatives of two meraspid degrees (M0, M1), of which the larger one exhibits well elevated axial rings (Fig. 3d). Likewise, pygidia of subsequent instars with four, five, or six 


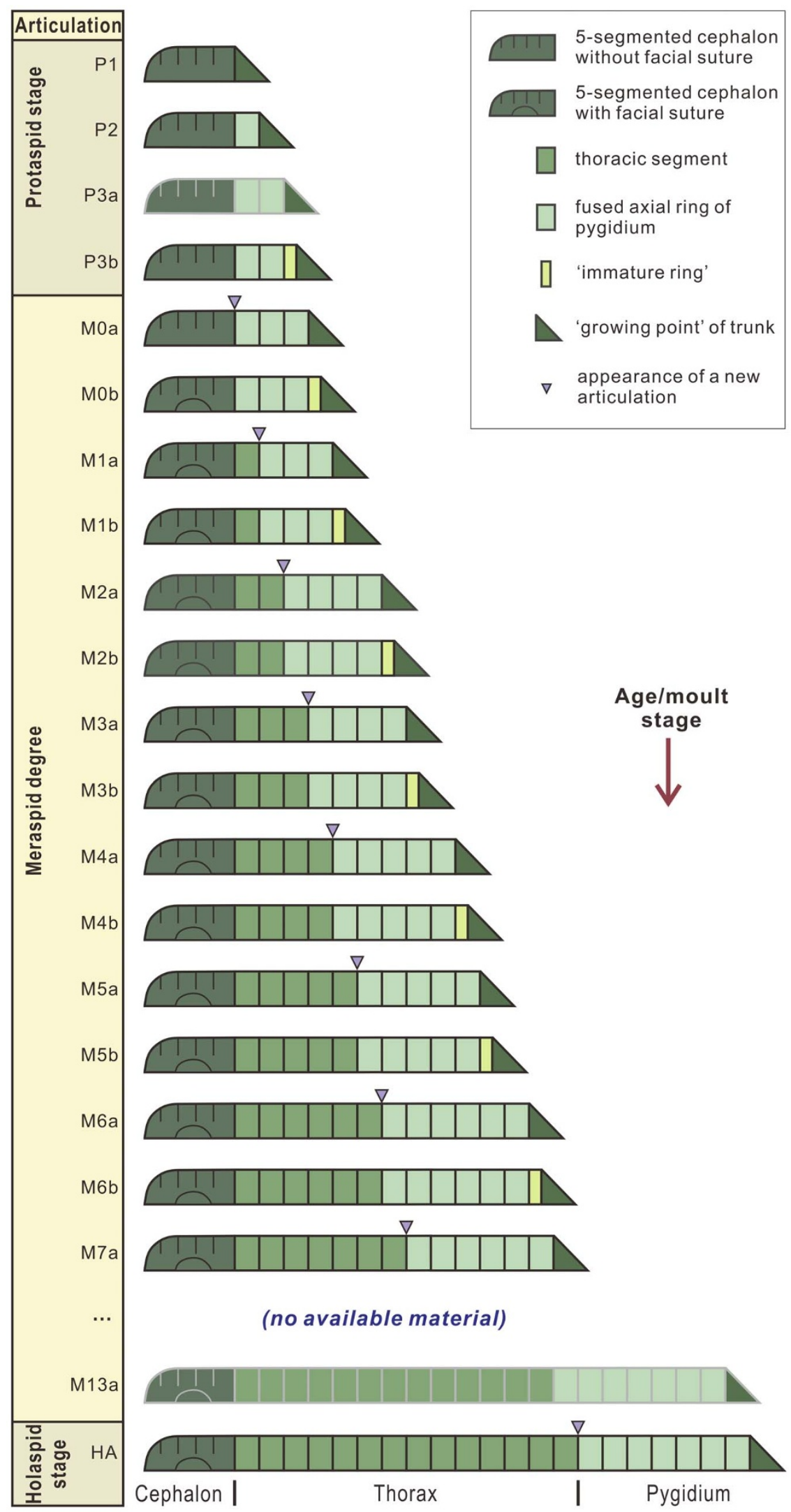

Figure 6 | Trunk segmentation schedules of Gunnia sp. Based on all measured early meraspides the growth rate for these instars is about 1.15 . Accordingly, this ratio is applied to define the subsequent meraspid degrees and holaspid stages. The expressing mode of development and abbreviations mainly following Hughes et al. ${ }^{14}$. 

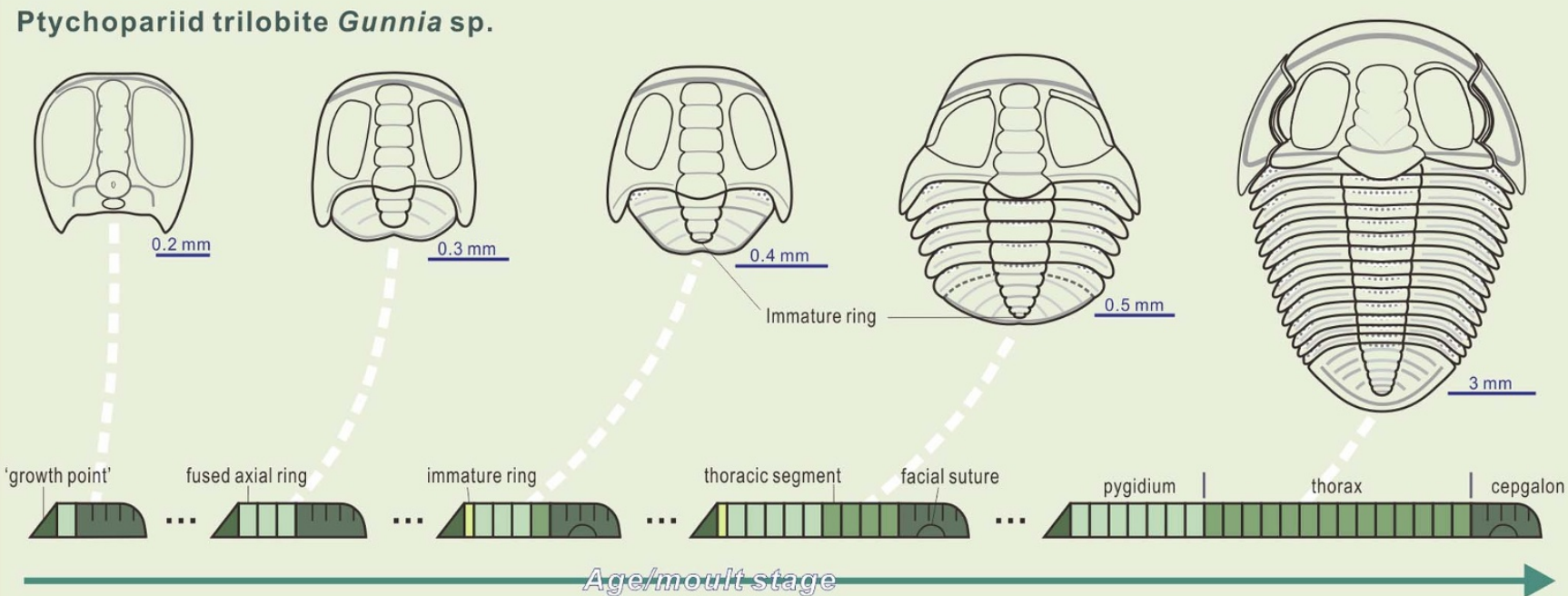

\section{Protaspis}

(larva)
Meraspides

(juveniles)
Holaspis

(adult)

Figure $7 \mid$ Development and trunk segmentation of Gunnia sp. The increase of pygidial rings is faster than that of thoracic segments, so that a later meraspis may bear more axial rings than the preceding one(s). Thoracic segment appears to occur in a punctuated manner, but the growth of an axial ring is a continuing process, first emerging as a tiny or even nearly invisible 'immature ring' to link two adjacent meraspid degrees.

axial rings are also of the same development pattern. That is, pygidia with four axial rings correspond to meraspid degree 2 (M2) and degree 3 (M3); pygidia with five axial rings correspond to meraspid degree 4 (M4) and degree 5 (M5). The regular pattern is well confirmed by the bivariate plots (Fig. 5b). However, the distribution is not exactly defined by size, sometimes pygidia with a different number of axial rings overlap or are irregularly scattered (e.g., Fig. 31, 3m). One interpretation is that a newly added axial ring at the beginning is always so tiny that is too difficult to firmly determine whether, to count it or not to count immediately leads two separate results. Perhaps the releasing process may have changed its pattern to some extent in later meraspid growth. To date we have no exact idea how the segment-releasing model would transfer from up to a maximum of three axial rings to of four, five and six. Such a transference must happen because a typical holaspid pygidium bears seven axial rings (Fig. 3n).

In summary some meraspid instars may have no thoracic segments released with growth, but the number of axial rings of the meraspid pygidium would increase constantly. In other words, meraspid degrees did not necessarily correspond to meraspid instars ${ }^{29}$. Here, as with the protopygidium of a protaspis, the transitory pygidium of Gunnia sp. also exhibits a marked increase of axial segments stages before the thorax is completed. In a previous study a similar growth schedule determined from Shumardia (Conophrys) salopiensis has been illustrated ${ }^{28}$.

\section{Discussion}

Most protaspides reported here, including those of Gunnia sp., are in general comparable to some adult-like protaspid larvae described by Speyer and Chatterton ${ }^{31}$, and most likely to have adopted a benthic mode of life. This is in accordance with the co-occurrence of these trilobite larvae together with some of their subsequent instars, including some holaspides (Fig. 4). In addition, the taphonomic features may infer an intricate surrounding environment, where numerous skeletal animal remains coexisting with rare scalidophoran embryos in Orsten-type preservation were assumed to have been buried in situ, or at least had not suffered long-distance transportation ${ }^{11}$.

Like other known trilobites, the head of Gunnia sp. displays a constant number of five segments throughout ontogenetic process.
In contrast, its meraspid pygidia vary greatly in size, morphology and the axial rings as reported here. Some basic features associated with their development are recognized: (i) With growth the axis of early meraspid pygidia would increase stably from three to seven rings, and instars with the same number of rings are roughly scattered into clusters (Fig. 5b). However, the size plots alone cannot exactly divide all instars into a series of growth degrees, since instars belonging to two adjacent degrees may overlap with each other. As our measurements indicate pygidia with three axial rings display a size range from 0.47 to $0.53 \mathrm{~mm}$ in width, which represents a size increasing ratio of 1.13. It should be pointed out that the ratio may increase but will not reduce with new discoveries of additional material, since the newly obtained specimens, either smaller or larger, can only increase the size range. Likewise, pygidia with four, five and six axial rings the measured size increasing ratios are $1.35,1.42$ and 1.50 respectively. Even if the average ratio would be 1.35 , some of the specimens that we identified as meraspid degree 6 (M6b) or holaspid instars (e.g. Fig. $3 n$ ) were to be included into a much earlier meraspid period. Instead, as is our practice here, to rely on a lower increasing ratio and refer them to two adjacent degrees tends to well explain the size ratio. (ii) During the meraspid period new thoracic segments would be released from the transitory pygidium one after another, whereas more axial rings being added to the pygidial axis. Two facts could be deduced from the pygidial development: first, the increase in number of the axial rings is obviously faster than that of the thoracic segments, so that a later meraspis bears more axial rings than the preceding one(s); secondly, the thoracic segment appears to occur in a punctuated manner, but the growth of an axial ring is a continuing process, this is why we may see such a pygidium may bear a tiny or even nearly invisible 'immature ring', or "not fully differentiated" as defined by Cederström et al. ${ }^{4}$. Logically, such a developmental feature must be present in every trilobite lineage, no matter whether it could be traced or not. On the other hand, the development of axial rings does not necessarily match the release of the thoracic segments in a one by one manner, as our finely preserved material has revealed here. On this basis, the trunk segmentation schedules of Gunnia sp. have been worked out (Fig. 6).

Phosphatization, as a unique process, has provided the highest fidelity of detail for various fossilized organisms, and has opened 
up a special window for us to look into an unexpected microworld. As examples some micron scale setae or setula $e^{32}$ and spine pores and lenses of compound eyes ${ }^{6}$ have been well illustrated. Moreover, as clearly shown here the continuing development of an axial ring terminally added to the axis could be traced through a series of forms from a tiny one (which might be too minute to see) to a fully developed ring. However, the ontogenetic stages and degrees of a trilobite taxon are conventionally divided into a series of punctuated groups based on its axial segments. It should be noted, however, that stages or degrees are really artifacts, which are hardly able to measure precisely the developmental process of a trilobite taxon; possible minute variations, such as an 'immature ring' - an axial ring in its halfway growth, linking two adjacent meraspid degrees are definitely recorded by the phosphatized material here (Figs. 3d, f, i, 7), but inevitably could be missed, especially when based on some crackout material with only submillimeter or even millimeter scale resolution. Accordingly doubts about the reliability of impressions in the exoskeleton to be the only crucial criterion for evaluation of trunk segmentation have been raised, along with a new hypothesis about the epimorphic development adopted by Cambrian eodiscoid trilobites $^{5}$, but so far have attracted little attention. Nonetheless, the artificial subdivision of stages and degrees do no more than construct a frame, based on which we can demonstrate the continuing variation exhibited by a trilobite during its development.

It is worth noting that the Cambrian Stage 5 Duyun fauna has yielded variously diversified trilobite protaspides (Fig. 4) as demonstrated here, but to date for many of them little has been learned about the likely corresponding post-protaspid instars. On this ground the phylogenetic affinity for these early trilobite instars remain uncertain, although in previous study such acid-liberated early instars could be assigned to coexisting subsequent instars of the same taxon ${ }^{33}$. This phenomenon may be referred to the exceptional taphonomic environment where only these small-sized protaspid instars are readily preserved-as usual phosphatization favors small objects, as in the tiny arthropods of the 'Orsten' fauna ${ }^{12,32}$. Alternatively, the later instars of these fossilized protaspides may have been adapted to diverse niches somewhere else, since the mode of life for these instars of various growth stages may be entirely different. Nevertheless, the taxonomic variety of these protaspid instars reported here infers the hidden majority of trilobites in the Duyun fauna.

\section{Methods}

By following the acid liberating procedure introduced by Shen et al. ${ }^{34}$, limestone nodules were digested in acetic acid of low concentration ( 5 per cent), and the insoluble residue was taken out of the acid solution every day (in summer) or every other day (in winter) depending on the seasonal fluctuation of temperature. Then all of the acid-liberated fossils were picked from the residue using a stereomicroscope.

The images of these fossils were taken (secondary electron: 10-20 kV) by using a scanning electron microscopy (model FEI Quanta 200), and digital images for fossils on the surface of crack-out specimens were captured by using a Leica M205C photomicroscope. All images were processed in Adobe Photoshop CS 4 .

1. Chatterton, B. D. E. \& Speyer, S. E. in Treatise on Invertebrate Paleontology, Part O, Arthropoda 1, Trilobita (ed. Kaesler, R. L.) 173-247 (Geol. Soc. Am. \& Univ. Kansas Press, 1997).

2. Fusco, G., Hughes, N. C., Webster, M. \& Minelli, A. Exploring developmental modes in a fossil arthropod: growth and trunk segmentation of the trilobite Aulacopleura konincki. Am. Nat. 163, 167-183 (2004).

3. Hughes, N. C. The Evolution of Trilobite Body Patterning. Annu. Rev. Earth Planet. Sci. 35, 401-434 (2007).

4. Cederström, P., Ahlberg, P., Clarkson, E. N. K., Nilsson, C. H. \& Axheimer, N. The Lower Cambrian eodiscoid trilobite Calodiscus lobatus from Sweden: morphology, ontogeny and distribution. Palaeontology 52, 491-539 (2009).

5. Zhang, X.-G. \& Clarkson, E. N. K. Trunk segmentation of Cambrian eodiscoid trilobites. Evol. Dev. 11, 312-317 (2009).

6. Zhang, X.-G. \& Clarkson, E. N. K. Phosphatized eodiscoid trilobites from the Cambrian of China. Palaeontographica (A) 297, 1-121 (2012).

7. Hunt, A. S. Growth, variation, and instar development of an agnostid trilobite. J. Paleontol. 41, 203-208 (1967).
8. Park, T.-Y. \& Choi, D. K. Ontogeny of the Furongian (late Cambrian) remopleuridioid trilobite Haniwa quadrata Kobayashi, 1933 from Korea: implications for trilobite taxonomy. Geol. Mag. 148, 288-303 (2011).

9. Zhang, X.-G. Ontogeny of an Early Cambrian eodiscoid trilobite from Henan, China. Lethaia 22, 13-29 (1989).

10. Zhang, X.-G. \& Clarkson, E. N. K. Ontogeny of the eodiscid trilobite Shizhudiscus longquanensis from the Lower Cambrian of China. Palaeontology 36, 785-806 (1993).

11. Zhang, X.-G., Pratt, B. R. \& Shen, C. Embryonic development of a Middle Cambrian (500 myr old) scalidophoran worm. J. Paleontol. 85, 898-903 (2011).

12. Shen, C., Aldridge, R. J., Williams, M., Vandenbroucke, T. R. A. \& Zhang, X.-G. Earliest chitinozoans discovered in the Cambrian Duyun fauna of China. Geology 41, 191-194 (2013).

13. Whittington, H. B. in Treatise on Invertebrate Paleontology, Part O, Arthropoda 1 , Trilobita (ed. Kaesler, R. L.) 1-85 (Geol. Soc. Am. \& Univ. Kansas Press, 1997).

14. Hughes, N. C., Minelli, A. \& Fusco, G. The ontogeny of trilobite segmentation: a comparative approach. Paleobiology 32, 602-627 (2006).

15. Gatehouse, C. G. Early Middle Cambrian trilobites of the Litchfield area, Northern Territories. Bull. Bur. Miner. Resour. Geol. Geophys. 80, 45-64 (1968).

16. Kruse, P. D. Cambrian palaeontology of the eastern Wiso and western Georgina Basins. Rep. Northern Territory Geol. Sur. 7, 1-58 (1990).

17. Yuan, J.-L., Zhao, Y.-L., Li, Y. \& Huang, Y.-Z. Trilobite fauna of the Kaili Formation (uppermost Lower Cambrian-lower Middle Cambrian) from southeastern Guizhou, South China 157-159 (Sci. \& Technol. Publ. House, 2002) [In Chinese].

18. Peng, S.-C. et al. Cambrian trilobites from the Parahio and Zanskar Valleys, Indian Himalaya. J. Paleontol. 83, 1-95 (2009).

19. Luo, H.-L., Jiang, Z.-W. \& Tang, L.-D. Stratotype section for Lower Cambrian stages in China. 141-142 (Yunnan Sci. \& Technol. Press, 1994). [In Chinese]

20. Zhang, W.-T. et al. Cambrian trilobite faunas of southwestern China. Palaeont. Sin. 1-342 (1980). [In Chinese with English summary].

21. Miller, J. Structure and function of trilobite terrace lines. Fossils Strata 4, 155-178 (1975).

22. Stitt, J. H. Functional morphology and life habits of the Late Cambrian trilobite Stenopilus pronus Raymond. J. Paleont. 50, 561-576 (1976).

23. Schmalfuss, H. Structure, patterns and function of cuticular terraces in trilobites. Lethaia 14, 331-341 (1981).

24. Whittington, H. B. Articulation and exuviation in Cambrian trilobites. Phil. Trans. Biol. Sci. 329, 27-46 (1990).

25. Månsson, K. \& Clarkson, E. N. K. Ontogeny of the Upper Cambrian (Furongian) olenid trilobite Protopeltura aciculata (Angelin, 1854) from Skåne and Västergötland, Sweden. Palaeontology 55, 887-901 (2012).

26. Clarkson, E. N. K., Ahlgren, J. \& Taylor, C. M. Structure, ontogeny, and moulting of the olenid trilobite Ctenopyge (Eoctenopyge) angusta Westergård, 1922 from the Upper Cambrian of Västergötland, Sweden. Palaeontology 46, 1-27 (2003).

27. Stubblefield, C. J. Notes on the development of a trilobite, Shumardia pusilla (Sars). Zool. J. Linn. Soc. Lond. 35, 345-372 (1926).

28. Hughes, N. C. Trilobite tagmosis and body patterning from morphological and developmental perspectives. Integr. Comp. Biol. 43, 185-206 (2003).

29. Fusco, G., Garland, J. R. T., Hunt, G. \& Hughes, N. C. Developmental trait evolution in trilobites. Evolution 66, 314-329 (2012).

30. Dai, T., Zhang, X.-L. \& Peng, S.-C. Morphology and ontogeny of Hunanocephalus ovalis (trilobite) from the Cambrian of South China. Gondwana Res. 25, 991-998 (2014).

31. Speyer, S. E. \& Chatterton, B. D. E. Trilobite larvae and larval ecology. Hist. Biol. 3, 27-60 (1989).

32. Müller, K. J. \& Walossek, D. Morphology, ontogeny, and life habit of Agnostus pisiformis from the Upper Cambrian of Sweden. Fossils Strata 19, 1-124 (1987).

33. Zhang, X.-G. \& Pratt, B. R. Early Cambrian trilobite larvae and ontogeny of Ichangia ichangensis Chang, 1957 (Protolenidae) from Henan, China. J. Paleontol. 73, 117-128 (1999).

34. Shen, C. et al. The search for Orsten-type fossils in southern China. Palaeoworld 22, 1-9 (2013).

\section{Acknowledgments}

This study was supported by the National Natural Science Foundation of China (41272027, 41302012) and Ministry of Education of China (20115301110001). We thank M. Tian and H.-Q. Zhang for specimen preparation.

\section{Author contributions}

C.S. and X.G.Z. conceived the project; X.G.Z. arranged fieldwork; X.G.Z., C.S., E.N.K.C. J.Y., J.B.H. and T.L. conducted research; C.S. wrote the manuscript; X.G.Z. and E.N.K.C. revised and edited the manuscript.

\section{Additional information}

Supplementary information accompanies this paper at http://www.nature.com/ scientificreports 
Competing financial interests: The authors declare no competing financial interests.

How to cite this article: Shen, C. et al. Development and trunk segmentation of early instars of a ptychopariid trilobite from Cambrian Stage 5 of China. Sci. Rep. 4, 6970; DOI:10.1038/ srep06970 (2014).

(c) (i) (2) (2) This work is licensed under a Creative Commons Attribution-NonCommercial- article are included in the article's Creative Commons license, unless indicated otherwise in the credit line; if the material is not included under the Creative Commons license, users will need to obtain permission from the license holder in order to reproduce the material. To view a copy of this license, visit http:// creativecommons.org/licenses/by-nc-sa/4.0/ 